\title{
A practical guide to the pharmacological and behavioral therapy of Narcolepsy
}

\author{
Christian Franceschini ${ }^{1} \cdot$ Fabio Pizza $^{2,4} \cdot$ Francesca Cavalli $^{2} \cdot$ Giuseppe Plazzi $^{3,4}$ (])
}

Accepted: 23 March 2021 / Published online: 22 April 2021

(c) The American Society for Experimental NeuroTherapeutics, Inc. 2021

\begin{abstract}
Narcolepsy is a rare, chronic, and disabling central nervous system hypersomnia; two forms can be recognized: narcolepsy type 1 (NT1) and narcolepsy type 2 (NT2). Its etiology is still largely unknown, but studies have reported a strong association between NT1 and HLA, as well as a pathogenic association with the deficiency of cerebrospinal hypocretin-1. Thus, the most reliable pathogenic hypothesis is an autoimmune process destroying hypothalamic hypocretin-producing cells. A definitive cure for narcolepsy is not available to date, and although the research in the field is highly promising, up to now, current treatments have aimed to reduce the symptoms by means of different pharmacological approaches. Moreover, overall narcolepsy symptoms management can also benefit from non-pharmacological approaches such as cognitive behavioral therapies (CBTs) and psychosocial interventions to improve the patients' quality of life in both adult and pediatric-affected individuals as well as the well-being of their families. In this review, we summarize the available therapeutic options for narcolepsy, including the pharmacological, behavioral, and psychosocial interventions.
\end{abstract}

Key Words Narcolepsy $\cdot$ Adults $\cdot$ Children $\cdot$ Pharmacological treatment $\cdot$ Cognitive behavioral treatment $\cdot$ Behavioral treatment

\section{Introduction}

Narcolepsy is a severe, chronic, and rare disorder, classified by the International Classification of Sleep Disorders Third Edition (ICSD-III) [1] within the central disorders of hypersomnolence $(\mathrm{CDH})$. Narcolepsy is categorized in narcolepsy type 1 (NT1) and in narcolepsy type 2 (NT2). NT1 is biologically marked by low cerebrospinal fluid hypocretin-1 levels (CSF hcrt-1), caused by the selective loss of hypothalamic neurons producing hypocretins, while NT2 is associated with normal levels of CSF hert-1 [1]. Narcolepsy core symptoms are excessive daytime sleepiness (EDS), cataplexy, sleep paralyses, hallucinations, and

Giuseppe Plazzi

giuseppe.plazzi@unimore.it

1 Department of Medicine and Surgery, University of Parma, Parma, Italy

2 Department of Biomedical and Neuromotor Sciences, Alma Mater Studiorum, University of Bologna, Bologna, Italy

3 Department of Biomedical, Metabolic and Neural Sciences, University of Modena and Reggio Emilia, Modena, Italy

4 IRCCS Istituto Delle Scienze Neurologiche Di Bologna, Bologna, Italy disrupted nocturnal sleep including frequent parasomnias. Cataplexy, defined as brief episodes of muscle atonia evoked by strong, mainly positive, emotions, is the pathognomonic symptom of NT1, while NT2 does not present with strictly defined cataplexy. Hypocretin-1 contributes to several functions, including circadian rhythm regulation, arousal and appetite control, as well as mood and behavior modulation [2-4]. This neurotransmitter also influences serotonin, histamine, dopamine, acetylcholine, GABA, and glutamate release $[5,6]$. The hypocretin-producing cell destruction contributes to most of the symptoms of narcolepsy, including EDS with sleep onset REM periods (SOREMPs), and other symptoms reflecting exaggerated REM sleep pressure such as cataplexy, sleep paralysis, hypnagogic/hypnopompic hallucinations, and REM sleep behavior disorder (RBD), all disclosing an intrinsic overlap between REM sleep and other states.

Narcolepsy onset usually occurs between 10 and 20 years of age, although the diagnosis is mostly established with a substantial delay (mean of 10-15 years). Narcolepsy, as a rare disease, has a prevalence that varies from geographical regions ranging from 0.02 to $0.06 \%$ in Europe and the USA [8], to $0.16-0.18 \%$ in Japan [7]. NT1 is considered more frequent than NT2, both in adults and in children [9], although 
real prevalence rates are missing and both disorders may be largely underestimated.

The etiology of narcolepsy is still unknown, but recent studies have suggested an autoimmune hypothesis. Indeed, NT1 is strongly associated with the human leukocyte antigen (HLA) DQB $1 * 0602$ allele and other genetic features pointing to a specific configuration of the immune system, and environmental risk factors, such as upper airway infections, may act as triggers leading to the destruction of hypothalamic hypocretin-producing neurons [10]. On the other hand, the pathophysiology of NT2 is still unclear, and within this diagnosis, some subjects may be in a prodromic phase of NT1 (with subsequent appearance of cataplexy) [11].

NT1 is also associated with significant medical comorbidities, such as obesity, precocious puberty (in the childhood onset form), and cardiovascular problems [12], as well as with psychological consequences all to psychiatric diseases [13]. Narcolepsy has a severe impact on patients' quality of life, with impairment in performance (e.g., at school, at work, at home) and psychosocial difficulties [14]. Patients also report additional non-sleep related aspects (i.e., decreased sexual activity or memory complaints) that negatively impact on disease perception and quality of life [15], and patients' unmet needs could benefit from new multidisciplinary management strategies $[16,17]$. Indeed, pharmacological symptom management per se may be insufficient to allow for normal everyday life, so behavioral therapies and interventions remain crucial.

This review seeks to offer clinicians an overview of the available pharmacological treatments for narcolepsy core symptoms (i.e., EDS and cataplexy) in adult and pediatric patients, and to provide a summary of some useful behavioral and psychosocial interventions.

\section{Methods}

The first author $(\mathrm{CF})$ performed a systematic literature search by using different scientific databases and keywords combinations, and selecting references published or available online in the timespan between 1975 and December 2020. The following scientific databases were used: PubMed, Web of Sciences, and PsycINFO. The following keywords were used alone and in combination to retrieve useful literature on narcolepsy treatment: narcolepsy, narcolepsy type 1 , narcolepsy type 2 , narcolepsy with cataplaxy, narcolepsy without cataplexy, treatment, pharmacotherapy, cognitive behavioral treatment (CBT), peer support, and counseling. The literature search provided a total amount of 4075 results from PubMed, 1716 from Web of Science, and 2344 from PsycINFO. The results obtained were then merged in order to avoid redundancies, and references were selected by applying the following criteria: (1) publication in
English; (2) availability of full text; (3) exclusion of reviews on narcolepsy management, and of single case reports/studies; and (4) author judgement of clinical relevance. The final citation list was then narrowed down to 137 references. We classified drugs as first-line treatments on the basis of the available evidence (i.e. clinical trials) and approval by the authorities.

\section{Pharmacological Treatment}

Pharmacological treatment for narcolepsy is necessary to manage symptoms and to improve patients' quality of life. Available treatments may act on one or multiple symptoms, namely, EDS, cataplexy, and disturbed nocturnal sleep. Given the diverse effect of the different drugs, the choice of a firstline approach should consider the complexity of individual patients, the burden of each symptom, the occurrence of multiple symptoms in combination, and the potential comorbidity/side effects taking into account sleep-wake habits and social patients' needs. In this review, we will distinguish between first- and second-line approaches on the basis of the available evidence (clinical trials, registration by authorities). Indeed, studies directly comparing the effects of different drugs on EDS and cataplexy are lacking; thus, the choice of the initial treatment should rely on the possibility to access the drug, on clinical judgement (including side effects), and on active discussion with the patients. We suggest starting the treatment with monotherapy, thus preferring the use of drugs acting on multiple symptoms in NT1 (i.e., sodium oxybate or pitolisant), and adding treatment(s) should depend on clinical judgement including careful follow-up with discussions with patients and caregivers. We prefer a patientcentered treatment decision (i.e., the choice to start with night-time versus daytime treatment) that takes into account individual habits and needs, so we do not suggest an a priori pharmacological treatment strategy.

For a number of drugs, and for the treatment of pediatric patients, approval is still pending at the European Medicine Agency (EMA) and/or at the Food and Drug Administration (FDA). Moreover, some treatments (antidepressants), albeit not registered for narcolepsy, have been extensively used for decades and have proven efficacious, so they are still prescribed off-label.

In this review, we will try to summarize the main treatments hitherto available for both adults and children with narcolepsy and the recommendations solely for adult patients with the aim of providing a practical guide for clinicians. We provide, in three tables, an overview of the available pharmacological treatment for EDS in adults (Table 1), for cataplexy in adults (Table 2), and for EDS and cataplexy in children (Table 3 ). 
Table 1 Therapy

recommendations for EDS in adults

\begin{tabular}{lllll}
\hline EDS in adult & Treatment & Dosage per day & FDA & EMA \\
\hline First line & Modafinil & $100-400$ up to $600 \mathrm{mg}$ & $\mathrm{X}$ & $\mathrm{X}$ \\
& Armodafinil & $100 \mathrm{up}$ to $250 \mathrm{mg}$ & $\mathrm{X}$ & \\
& Pitolisant & 9 up to $36 \mathrm{mg}$ & $\mathrm{X}$ & $\mathrm{X}$ \\
& Sodium oxybate & $4.5-9 \mathrm{~g}$ (split dose at night) & $\mathrm{X}$ & \\
& Solriamfetol & 75 up to $150 \mathrm{mg}$ & $\mathrm{X}$ & $\mathrm{X}$ \\
Second line & Methylphenidate & $10-40$ up to $60 \mathrm{mg}$ & $\mathrm{X}$ & $\mathrm{X}$ \\
& Dextroamphetamine & & & $\mathrm{X}$ \\
& Adderall & 5 up to $60 \mathrm{mg}$ & & $\mathrm{X}$ \\
& Evekeo & & $\mathrm{X}$ \\
\hline
\end{tabular}

\section{EDS Pharmacological Treatment in Adults}

\section{First-Line Treatments}

\section{Modafinil}

Modafinil is a weak inhibitor of dopamine reuptake that leads to an increase in extracellular dopamine. Although it has found that modafinil selectively stimulates wakegenerating sets in the hypothalamus [18], its mechanism of action is still largely unknown [19]. At the dosage of 200-400 mg/day, modafinil improves subjective EDS and objective vigilance as measured by sleep latencies on Maintenance of Wakefulness Test (MWT), a finding confirmed by positive changes at the Clinical Global Improvement of Change (CGI-C) [20-24].

Modafinil treatment usually starts with $100 \mathrm{mg}$ (in the morning) and can be titrated gradually to $200 \mathrm{mg}$ in a split dose in the morning (at awakening and at lunch time). After several weeks, the dose can be increased to $200+200 \mathrm{mg}$ [23, 24].

Approved by the FDA and EMA both for adult narcolepsy patients, modafinil is considered a good therapy because of a low addiction potential and mild side effects-generally headache, nausea, tension/anxiety, and insomnia [25-29]. Modafinil decreases the efficacy of oral contraceptives; thus, higher ethinylestradiol or alternative contraceptive methods are suggested [30].

\section{Armodafinil}

Armodafinil is the active R-enantiomer of modafinil and has a longer half-life. Armodafinil has the effect of reducing EDS in narcolepsy with a significant improvement in both MWT sleep latencies (1.3 to $2.6 \mathrm{~min}$ ) and in the Epworth Sleepiness Scale (ESS) score (3.8 to 4.1). [31]. Most common side effects include headache, nausea, dizziness, and decreased appetite. Armodafinil has been approved by the FDA in treating narcolepsy adult patients [20, 21]. Its recommended dosage should start with a single dose of $100 \mathrm{mg}$ in the morning up to a maximum of $250 \mathrm{mg} / \mathrm{day}$.

\section{Pitolisant}

Pitolisant is a selective $\mathrm{H} 3$ receptor competitive antagonist/ inverse agonist. Pitolisant acts at the presynaptic level by blocking the auto-inhibiting activity of histamine and H3R agonists on endogenous histamine release and leading to increased histamine release. Histaminergic neuron activity in the brain is involved in a large variety of functions, including wakefulness, attention, and memory [32-35]. Pitolisant has proven to have a no lesser efficacy on EDS compared to modafinil [32] and has also proven efficacious in decreasing cataplexy [33, 34]. The efficacy on EDS has been assessed on subjective EDS (ESS improvement of 4-6 points), and on secondary outcomes, namely objective vigilance (MWT) and CGI-C. In adults, pitolisant has been approved by the
Table 2 Therapy recommendations for cataplexy in adults

\begin{tabular}{lllll}
\hline Cataplexy in adults & Treatment & Dosage per day & FDA & EMA \\
\hline First line & Sodium oxybate & $4.5-9 \mathrm{~g}$ (split dose at night) & X & X \\
& Pitolisant & 9 up to $36 \mathrm{mg}$ & $\mathrm{X}$ & $\mathrm{X}$ \\
Second line & Venlafaxine & 37.5 up to $225 \mathrm{mg}$ & & \\
& Fluoxetine & $10-20$ up to $60 \mathrm{mg}$ & & \\
& Citalopram & $10-20$ up to $40 \mathrm{mg}$ & \\
& Clomipramine & $10-25$ up to $75 \mathrm{mg}$ & \\
\hline
\end{tabular}


Table 3 Therapy recommendations for EDS and cataplexy in children

\begin{tabular}{lllll}
\hline Therapy for children & Treatment & Dosage per day & FDA & EMA \\
\hline EDS & Modafinil & 50 up to $400 \mathrm{mg}$ & & \\
& Armodafinil & 50 up to $400 \mathrm{mg}$ & & \\
& Pitolisant & 4.5 up to $36 \mathrm{mg}$ & & \\
& Sodium oxybate & $2-8 \mathrm{~g}$ (split dose at night) & $\mathrm{X}$ & $\mathrm{X}$ \\
& Methylphenidate & 10 up to $40 \mathrm{mg}$ & & \\
& Dextroamphetamine & 2.5 up to $20 \mathrm{mg}$ (twice a day) & & $\mathrm{X}$ \\
Cataplexy & Sodium oxybate & $2-8 \mathrm{~g}$ (split dose at night) & & \\
& Pitolisant & $4.5 \mathrm{up} \mathrm{to} 36 \mathrm{mg}$ & & \\
& Imipramine & $10-100 \mathrm{mg}$ & & \\
& Clomipramine & $10-150 \mathrm{mg}$ & & \\
& Protriptyline & $2.5-5 \mathrm{mg}$ & & \\
& Fluoxetine & $10-30 \mathrm{mg}$ & & \\
& Venlafaxine & $3.75-75 \mathrm{mg}$ & \\
\hline
\end{tabular}

EMA and FDA for the treatment of excessive daytime sleepiness (EDS) or cataplexy in adult patients with narcolepsy [36].

For pitolisant dosage, the EMA recommends a singledose intake during breakfast starting from $9 \mathrm{mg}$ and titrating up to $36 \mathrm{mg} /$ day in few weeks. The most effective dosage, prescribed by EMA, is commonly $36 \mathrm{mg} / \mathrm{day}$, and its complete efficacy is reached in a couple of weeks, with little evidence of a clinical long-term efficacy. FDA has approved pitolisant at a lower dosage: starting from $8.9 \mathrm{mg} /$ day reaching $17.8 \mathrm{mg}$ per day after 1 week. The maximum daily dosage for FDA is $35.6 \mathrm{mg}$, after 2 weeks. Pitolisant was generally well tolerated and showed low abuse potential. Commonly reported side effects were headache, insomnia, abdominal discomfort, nausea, and irritability [32, 33].

\section{Sodium Oxybate or Gamma Hydroxybutyrrate}

Sodium oxybate is the sodium salt of $\gamma$-hydroxybutyrate, an endogenous metabolite of the inhibitory neurotransmitter GABA. Sodium oxybate is a gamma-hydroxybutyric acid B-subtype (GABAb) receptor agonist. GABAb receptors within the central nervous system are diffused in the hypothalamus and basal ganglia. Although the mechanism of action of sodium oxybate is unclear, the drug showed a strong effect in promoting nocturnal slow-wave sleep, suppressing REM sleep and leading to an overall improvement of sleep efficiency $[37,38]$. Sodium oxybate has shown efficacy in reducing subjective EDS and increasing objective alertness with a median increase of $>10 \mathrm{~min}$ at MWT [39, 40]. Although the mechanism of action of sodium oxybate on EDS has not been elucidated, it may be related to the effect on nocturnal sleep as well as its biphasic dopaminergic activity with immediate suppression promoting sleep, and subsequent release promoting wakefulness. Sodium oxybate also showed efficacy on cataplexy [41, 42] and disturbed nocturnal sleep [37, 38]. For the more appropriate dosage and best effect on EDS, it is often necessary to wait several weeks in order to allow an individualized titration.

Sodium oxybate is available only in liquid form. The drug has a short half-life (40-60 min), and therefore should be taken in two doses per night. The dosage usually starts with $4.5 \mathrm{~g} /$ night (split into two doses of $2.25 \mathrm{~g}$ the first at bedtime, the second $2.5-4 \mathrm{~h}$ after the first intake, so the patient must be woken up to take the second dose) for 4 weeks and then progressively increasing $1.5 \mathrm{~g} / \mathrm{night}$ per week to reach the target dosage of 6-9 g/night. According to this titration scheme, EDS improvements should appear in 4-8 weeks from the treatment start.

Side effects for this drug are nausea, dizziness/confusion, weight loss, enuresis, anxiety, and depressive symptoms. Some concerns are related to the potential interactions with other sedating drugs, to the possible depression of the respiratory drive in patients with sleep-related breathing disturbances or lung comorbidities, to the possible misuse as a "date rape" drug, as well as to the important salt load that may have cardiovascular effects.

The FDA has approved sodium oxybate for adults and children narcolepsy patients over 7 years old in narcolepsy for the treatment of EDS or cataplexy, while the EMA has approved the drug for the treatment narcolepsy with cataplexy in adult patients, adolescents, and children from the age of 7 years $[43,44]$.

\section{Solriamfetol}

Solriamfetol (75 up to $150 \mathrm{mg} /$ day) is a selective inhibitor of the reuptake of dopamine and norepinephrine. This new treatment is different from other wake-promoting agents for its dual action. Moreover, it does not promote the release of monoamines as amphetamines, thus leading to lower risk 
of abuse and withdrawal effects. Solriamfetol efficaciously reduced subjective EDS (ESS), and improved vigilance (MWT) with a dose-response effect $[45,46]$. The effect was confirmed also in long-term clinical trials [47].

Solriamfetol has been approved for the adult treatment of EDS by FDA and EMA in adult patients with narcolepsy [48]. Commonly reported side effects include headache, nausea, diminished appetite, nasopharyngitis, dry mouth, and anxiety.

\section{Second-Line Treatments}

\section{Methylphenidate}

When other wake-promoting agents show no effectiveness, methylphenidate represents a second-line option. Methylphenidate increases dopamine and norepinephrine transmission. Although widely used, only a few studies $[49,50]$ have reported significant differences in the methylphenidate effect on the ability to stay awake and active in narcolepsy patients. In clinical practice EDS improved within few days of lowest dose administration $(10 \mathrm{mg})$, while a dose of $60 \mathrm{mg}$ and higher can be used to achieve a clinically meaningful response [20, 21].

Methylphenidate has been approved for treatment in adult NT1 and NT2 patients by the EMA (but it is not registered in all EU countries) and the FDA.

Side effects of methylphenidate include tachycardia, hypertension, sweating, palpitations, irritability, hyperactivity, mood swings, weight loss, anorexia, and insomnia. Albeit mild, there are risks of abuse and dependence for methilphenidate.

The dosage starts with a dose of 10-20 $\mathrm{mg}$ in the morning at breakfast and additional $10-20 \mathrm{mg}$ at lunch, to reach the maximum dosage of $60 \mathrm{mg}$, usually taken in $2-4$ portions during the daytime [50].

\section{Amphetamines and Other Therapeutic Options}

Amphetamines are another treatment option for EDS [20, $21]$. They increase the concentration of dopamine and norepinephrine, and are approved in some European countries [20]. Treatment with dextroamphetamine usually starts with $10 \mathrm{mg}$, and therapeutic dosages may reach a maximum of $60 \mathrm{mg}$ per day [49]. Other options include selegeline and reboxetine [51, 52]. Amphetamines may induce not only common side effects (irritability, aggressiveness, insomnia, and hypertension) but also severe consequences (abnormal movements, cardiac arrhythmias, and psychotic symptoms) that make their use dangerous especially in patients with cardiovascular comorbidity. Moreover, although rare in narcolepsy, amphetamines suffer from a risk of abuse [49, 51, 52].
FDA recently approved two different combinations: one associates amphetamine and dextroamphetamine (Adderall ${ }^{\mathrm{TM}}$ ), and another has amphetamine sulfate as the main active ingredient $\left(\right.$ Evekeo $\left.^{\mathrm{TM}}\right)$.

\section{Cataplexy Pharmacological Treatment in Adults}

\section{First-Line Treatments}

\section{Sodium Oxybate}

Sodium oxybate is recognized as an efficacious drug against cataplexy [41, 42]. Several clinical trials, including data on a prolonged follow-up of 18 months, showed a significant decrease in cataplectic attacks after a few weeks of therapy with a dose-dependent effect [53-56]. Importantly, abrupt sodium oxybate withdrawal does not induce a rebound effect. The FDA has approved sodium oxybate for adults and children narcolepsy patients over 7 years of age for the treatment of EDS or cataplexy, while the EMA approved the drug for the treatment of narcolepsy with cataplexy in adult patients, adolescents and children from the age of 7 years $[43,44]$.

\section{Pitolisant}

Pitolisant has proven efficacy in reducing daily cataplexy attacks [57]. A randomized double-blind and placebo-controlled trial conducted on 105 NT1 patients taking pitolisant disclosed an important decrease in cataplectic attacks [33], an effect confirmed in long-term studies [58].

In adults, pitolisant has been approved by EMA and FDA for the treatment of excessive daytime sleepiness (EDS) or cataplexy in adult patients with narcolepsy [36].

\section{Second-Line Treatments}

\section{Venlafaxine}

Although it is not approved, venlafaxine is a selective serotonine-norepinephrine reuptake inhibitor widely prescribed in NT1 patients, and only on the basis of clinical recommendations it can be considered a first-line pharmacological approach [20,21]. Venlafaxine has an effect as an anticataplectic that reaches its peak in few days. It is well tolerated and has some typical side effects: increased blood pressure, headache, dry mouth, nausea, and dizziness.

Its dosage starts with $37.5 \mathrm{mg}$ reaching the maximum dose of $225 \mathrm{mg}$ in the morning [60]. Patients should be advised that abrupt withdrawal can produce a severe rebound effect up to the occurrence of subcontinuous invalidating cataplexy episodes, a condition defined as "cataplectic status" [61]. 
Other Antidepressants: Fluoxetine, Citalopram, and Clomipramine

As second-line treatments for cataplexy in NT1, there are selective serotonin reuptake inhibitors (SSRIs), especially fluoxetine (10-20 up to $60 \mathrm{mg} /$ day) and citalopram (10-20 up to $40 \mathrm{mg}$ /day) [20, 21]. Common side effects are excitation, gastrointestinal problems, insomnia, and sexual difficulties, and they should not be underestimated, because they can limit applicability in clinical practice $[49,59,62$, 63]. As for venlafaxine, abrupt withdrawal can lead to a severe rebound effect [64]. Their use should considered with extreme caution by physicians especially when used with young patients.

Also, clomipramine, a tricyclic antidepressant, is used with a daily dosage that ranges from 10-25 up to $75 \mathrm{mg} /$ day. Since the 1960s, several observations have confirmed clomipramine effect on reducing cataplectic attacks, but the drug has not been officially approved by the EMA and the FDA [20, 21, 65-67]. Antidepressants (fluoxetine, citalopram, and clomipramine) have only been approved in Germany.

Clomipramine suffers from common side effects, such as dry mouth, sweating, constipation, diarrhea, tachycardia, weight gain, hypotension, difficulty in urinating, and impotence.

\section{EDS Pharmacological Treatment in Childhood}

Nowadays, within all the EDS treatments, only sodium oxybate has been approved by FDA and EMA for treatment in children and adolescents. The other treatments for pediatric patients are considered only at empirical level as off-label $[68,69]$.

\section{Modafinil and Armodafinil}

Both the treatments are used off-label by physicians for patients under the age of 16 , because they have not yet been approved by the FDA for young people below the age of 16 [20, 21]. For children, the daily dosage of modafinil and armodafinil is $50-400 \mathrm{mg} /$ day in two doses at the morning to support children in school performance and after lunch, for after-school activities and homework. In case of sudden withdrawal, modafinil does not cause EDS rebound. Commonly reported side effects in young patients are headache, nausea, and vomiting. Moreover, a single case of Stevens-Johnson syndrome has been reported in a patient taking modafinil [70]. Steven-Johnson syndrome is a delayed hypersensitivity reaction that develops from a few days to weeks after beginning the therapy, and it appears as red or purple skin rash that gradually spreads. The only piece of evidence is a level 4 study by Ivanenko and colleagues [71]. Modafinil therapy in children and adolescents contributes to a subjective improvement in EDS. Furthermore, the study showed objective improvement in the average sleep latency on the MSLT from a baseline of $6.6 \pm 3.7$ to $10.2 \pm 4.8 \mathrm{~min}$.

\section{Pitolisant}

Up to now, a few uncontrolled data have reported the efficacy and safety of pitolisant in reducing EDS in children and adolescents. The dosage for children is $4.5 \mathrm{mg}$ up to $36 \mathrm{mg}$ per day.

Minor side effects have been reported (insomnia, headache, hot flushes, leg pain, and hallucinations), and all but insomnia were transient [72].

\section{Sodium Oxybate}

Sodium oxybate is used for NT1 treatment in children, for its effects on reducing EDS and cataplexy. The drug is used in monotherapy or in association with other stimulants [73]. Its efficacy on EDS and cataplexy has been demonstrated in $88 \%$ of NT1 children $[44,74]$, but sodium oxybate side effects maintain a high-risk ratio: sleep walking, sleep enuresis, exacerbation of sleep apnea, tremor, constipation, exacerbation of pre-existing depressive tendencies, weight loss, nausea, irritability, and episodes of sleep drunkenness. Abrupt drug withdrawal does not cause rebound effects [73]. Recent data have also shown a positive effect on sleep disruption and on REM sleep behavior disorder [74-76].

Administration of this treatment requires particular care. In fact, dispensation is made from central pharmacies, and before making out, the prescription clinicians and physicians have to register and train patients or their caregiver for proper use. This high level of care required for the drug assumption is due to the risk of misuse/abuse reported in several clinical cases. Therefore, the patient and his/her family need proper training before starting the treatment. It is recommended that a family member should be in attendance during the drug administration and should be responsible for storing the medication in proper locked place. Given the liquid form of the drug and its salty taste, it can be administrated with addition of flavor. The right dosage varies from 2 to $8 \mathrm{~g}$ per night, and the drug should be given in two administrations: one before falling asleep and the other one 3-4 $\mathrm{h}$ after the first dose.

\section{Amphetamines and Methylphenidate}

Amphetamine (dextro-amphetamine) and andmethylphenidate enhance dopaminergic and norepinephrinergic activity $[20,21]$. Both drugs are also used to treat attention-deficit/ hyperactivity disorder in children and adults. Recommended dosages are 2.5 to $20 \mathrm{mg}$ twice a day for dextro-amphetamine 
and 10 to $40 \mathrm{mg}$ for methylphenidate. Their use in adults is supported by three phase 2 and four level 5 studies that support the effectiveness of those stimulants in treating EDS [21]. Side effects include tics, anorexia, headache, nervousness, insomnia, and weight loss [77]. Their use in children below the age of six is not approved by FDA and is discouraged in children with a diagnosed heart disease [78, 79]. Moreover, while rare in narcolepsy, amphetamines and methylphenidate suffer from a risk of abuse.

\section{Cataplexy Pharmacological Treatment in Childhood}

To date, only sodium oxybate has been approved by FDA and EMA as a treatment for cataplexy in children and adolescents. Thus, the selection of medications in the pediatric population is based only on an empirical, off-label, basis [69].

\section{Sodium Oxybate or Gamma Hydroxybutyrate}

The information about sodium oxybate's effect on cataplexy in childhood is included in the previous paragraph "EDS pharmacological treatment in childhood."

\section{Pitolisant}

Ongoing trials are evaluating the efficacy and safety profile of pitolisant in children, and to date, a slight improvement of cataplexy frequency and severity has been reported in children in an uncontrolled case series [72].

\section{Selective Norepinephrine Reuptake Inhibitors}

Venlafaxine is commonly used against cataplexy with a dosage of 37.5-75 mg per day [20, 21]. Due to the high risk of suicide reported in adolescents, the administration of venlafaxine for adolescents and children must be strictly controlled [80]. In addition, side effects due to the interactions with monoamine oxidase inhibitors include dizziness, headache, and insomnia. Further studies are warranted, given that only a few observational data are available with 2-year follow-up [81, 82].

\section{Tricyclic Agents}

In addition, imprimine, clomipramine, and protryptiline are commonly used for control cataplexy. Their dosages are, respectively, $10-100 \mathrm{mg}, 10-150 \mathrm{mg}$, and $2.5-5 \mathrm{mg}$ per day. The most commonly reported side effects are dry mouth, blurring, drowsiness, orthostatic hypotension, and weight gain $[20,21]$.

\section{Selective Serotonin Reuptake Inhibitors}

Within SSRI, the most typically used agent is fluoxetine with a daily administration dosage of $10-30 \mathrm{mg}[20,21]$. Commonly reported side effects are nervousness, insomnia, and tremor. As for other antidepressants, sudden drug withdrawal or irregular intake may induce a rebound of cataplexy up to "status cataplecticus" [83].

\section{Immunotherapy}

Findings reported associations that support an autoimmune mechanism underlying the onset of NT1 that suggest the use of immunomodulation therapy with intravenous immunoglobulin G (IVIG) close to disease onset. Only a few studies [84-87] have analyzed IVIG therapeutic efficacy in early onset NT1cases. To date, the results have been controversial due to the small sample size, open label design, and self-reported observations. However, an improvement in cataplexy frequency and severity, as well as in EDS, was reported, but further data are required to exclude the possibility of a spontaneous improvement in NT1 symptoms during the disease course [88]. Overall, despite some promising results, further studies should address the role of immunotherapy in NT1 [89].

\section{Non-pharmacological Treatment}

Psychological difficulties are one of the main issues affecting narcolepsy patients, who often report a significantly lower quality of life [14, 90-92]. In fact, narcolepsy is associated with some difficulties including work performance, sexual activity [93], higher risk of car accidents [94], neuropsychiatric alterations [95-100], and psychological disorders [97-101].

Non-pharmacological treatments are regularly used to manage EDS, either as an adjunct to drug therapy or as an alternative treatment. Several authors have reported that medications alone may not completely resolve EDS, in particular about $15 \%$ of patients with narcolepsy depend on medications alone [98] and up to 54\% of these patients require behavioral strategies [102-104].

Although only a little evidence on the effect of daytime napping on EDS in NT1 is available [105], the importance of cognitive and behavioral therapies for narcolepsy treatment is fully recognized from a clinical point of view. The American Academy of Sleep Medicine is the only institution presenting treatments other than the pharmacological ones [20], while scheduled naps, sleep hygiene, balanced diet, and physical activities are within the clinical guidelines of associations of sleep medicine or neurology from several 
countries. Among these, both the UK and European Association of Neurology for Europe, the American Academy of Sleep Medicine for North America, and the Brazilian Sleep Society $[20,21,106,107]$ agree on the importance of cognitive and behavioral actions to contain narcolepsy symptoms, reduce the negative effects, and gain a better compliance with drug therapy. In particular, the guidelines proposed by the UK Consensuses [106] suggest a symptomatologic approach, focused on increasing the patient's knowledge of his/her disease, integrated with psychological support, in planning scheduled naps, promoting regular nocturnal sleep duration, and helping with the management of work, the home and recreational activities.

\section{Cognitive Behavioral Therapy}

Several countries recommend use of cognitive and behavioral strategies as adjunctive treatment to reduce the patient's dysfunctions, to obtain a better response, to and decrease the amount of drugs that need to be administered. Within behavioral sleep medicine (BSM), cognitive behavioral therapy for insomnia (CBT-I) has gained prominence as an empirically supported treatment for chronic insomnia. Up to now, less attention has been paid to develop and validate methods for disorders related to the hypersomnia family.

The main goals of CBT are to apply strategies focused on the resolution of symptoms, identify, and modify dysfunctional thought patterns with negative influence on behaviors and emotions. In particular, it is possible to help narcoleptic patients to identify and improve dysfunctional cognitions, enhance treatment adherence, take medications at the appropriate times, maintain good sleep hygiene, and take scheduled naps to address the psychosocial needs of such patients. This sort of therapy should be performed only by psychologists, interested in BSM, who graduated from a school with an AASM-accredited sleep program or with a teacher with experience in sleep, and who completed a sleep-related internship at a local sleep clinic.

Currently, there is an insufficient number of clinical studies on patients with narcolepsy that present a standardized and unambiguous protocol on how to manage symptomatology and its psychosocial functioning. Patients under CBT also receive help to manage the impact that narcolepsy has on their quality of life, ranging from emotional to social levels [108] and health-related stigma [109].

A randomized study reported that patients undergoing cognitive therapy showed significant improvements in the subjective perception of their quality of life (i.e., physical function, social function, vitality, and emotional role) and EDS, through self-reported measures (i.e., the ESS, Ullanlinna Scale, SF-36) [110-112]. The aim of this study was to evaluate whether a multicomponent (sleep satiation, nap training, cognitive restructuring, and problem-solving techniques) treatment could provide better results than the standard treatments alone (control group, 6 months, and 1 year on treatment).

Other studies tried to assess how effective the cognitive measures could be in coping with narcolepsy [113]. To estimate the extent to which CBT-based on cognitive restructuring intervention-was effective, these authors measured quality of life, beliefs, and attitude of narcolepsy patients, finding that patients under CBT had significantly superior $(p<0.005)$ post-treatment assessment scores than the control and drug treatment groups.

Finally, Ong et al. have developed a novel CBT for hypersomnia (CBT-H) in people with $\mathrm{CDH}$ and co-occurring depressive symptoms, using an online access model for delivery and assessment [114]. At baseline and posttreatment, 35 adults with a diagnosis of $\mathrm{CDH}$ were evaluated with Patient-Reported Outcomes Measurement Information System measures, ESS, and other patient-reported outcomes. Moreover, they received a six-section CBT-H, delivered individually or in a small group, using a telehealth online platform by an expert psychologist therapist. Cognitive interventions were aimed at processing changes in personal identity or functional limitations that emerged due to symptoms of $\mathrm{CDH}$. Topics included treating the stigma of CDH diagnosis, implications of CDH symptoms on self-perception, professional goals and interpersonal relationships, and specific coping skills to manage mood and anxiety, associated with the unpredictability of $\mathrm{CDH}$ symptoms.

Further research and clinical trial are needed to support the sporadic clinical evidence of CBT programs in narcolepsy.

\section{Behavioral Treatment for EDS}

Such techniques represent a useful tool for improving or controlling sleep disorder behaviors. Several studies have shown $[20,21]$ that planning two or three short (15-20 min) naps at specific times of the day (scheduled daytime naps) is the most common behavioral recommendation [102, 115-119]. Naps should be short to avoid sleep inertia at reawaking $[102,105,106,115,119-121]$.

Nevertheless, this is just an indication, since not every narcoleptic patient benefits from short naps [115] Indeed, some patients could benefit from longer naps [115]. Moreover, other studies have suggested an overall benefit in daytime alertness, when scheduled naps are associated with regular nocturnal bedtime [102].

Another strategy for improving EDS is reaching sleep satiation through sleep extension. Based on the sleep homeostasis theory, sleep satiation technique requires scheduled 
extension of nocturnal sleep: for 2 weeks from 10.00 p.m. to 6.00 a.m. [122]. This technique requires the detection of the behavior frequency: identifying the degree of sleepiness and filling in a sleep diary that determines the number of sessions. After that, continuous 1-day episodes are scheduled without light-dark cues. Improvements that follow naps and scheduled nocturnal sleep extension can be clarified by this behavioral disposition.

Physical activity may also has a positive effect on EDS. Experimental studies (in mice) showed that wheel running increased wakefulness in not only hypocretin knockout, but also cataplexy [123]. A relationship between physical activity and quality of sleep was recorded in healthy adolescents. This led to the hypothesis that physical activity may stabilize the circadian rhythm, following the improvement in sleep quality, but the mechanism that explain this relationship remains under investigation.

In any case, an actigraphic study with NT1 children and adolescents detected that regular physical activity was associated with significant differences in children's sleepiness (lower subjective ESS-CHAD scores) and sleep/wake profile (fewer daily naps and less time asleep during daytime), but without triggering cataplexy [124].

In addition, narcoleptic patients also reported the utility of controlling their environment (e.g., avoiding hot rooms, keeping the room cool, seeking fresh air), engaging themselves in certain activities (e.g., being active in conversations, avoiding boring events, restricting evening events), and different physical activities (e.g., pinching oneself and clenching one's teeth) on EDS management [103, 111].

Broughton and Murray reported the success of these selfbehavioral stimulations in six out of 13 patients [125]. Furthermore, a survey evaluating the most common behavioral strategies found that daytime napping (86\%), scheduled nocturnal sleep (i.e., bedtime and wake-up time, $76 \%$ ), caffeine use $(76 \%)$, physical exercise $(57 \%)$, diet (50\%), temperature manipulations (42\%), chewing gum (30\%), nicotine $(23 \%)$, mindfulness $(21 \%)$, and yoga (18\%) were efficacious in managing EDS [99].

However, no clinical trials have addressed the efficacy of behavioral approaches on EDS in narcolepsy, and therefore, further research is needed on patients.

\section{Cognitive and Behavioral Treatment for Cataplexy}

CBT is also used for cataplexy treatment, particularly through systematic desensitization, that helps patients to find coping strategies to manage their emotions. This symptomatic strategy - an evidence-based therapy approach that combines relaxation techniques with gradual exposure to help overcome a particularly stressful condition-gradually reduces the impact of the emotional triggering stimulus by guiding the patient through situations where the frequency and intensity of this stimulus increase. To arrange the systematic desensitization technique, it is necessary for stressful and hyperactivating stimuli (e.g., like a funny video), to be previously assessed by patients, confirming that they are triggers for cataplexy. Then, clinicians ask the patients, in a state of deeply relaxation, to figure in their mind the hyperactivating stimulus, through the illustration of the situations in all their details [126].

Within the CBT approach, other procedures for cataplexy reduction are the emotional techniques (e.g., avoiding emotional experience, excitement) for the management of symptoms and the stimulus satiation, in which the clinician maintains what reinforces the cataplectic behavior in the patient until it loses its effect [126]. In a qualitative study on the cataplexy experience, some patients reported a sort of ability to control the attacks by focusing on the inhibition/avoidance of the emotional triggers (such as laughter), or seeking support or trying to sit down, to avoid falling to the ground [127].

This approach should be performed only by a psychologist experienced in behavioral sleep medicine.

\section{Counseling}

Psychological counseling offers a space to improve symptom management and treatment for both patients and relatives, through proper education and information about the disease, particularly when the diagnosis has just been made. With psychological counseling patients can better understand how narcolepsy can change their life and accordingly develop strategies to deal with it. Through psychological counseling patients can be informed about all the available pharmacological and behavioral therapies (e.g., good sleep hygiene) and their outcomes, and finally other lifestyle factors that could affect the symptoms (e.g., the influence of alcohol on EDS) [128].

Furthermore, researchers are becoming increasingly aware of the importance of peer support, as a form of psychosocial support offered by someone with experiential knowledge of the disease [128]. With peer support, patients can also face the sense of isolation, improve their knowledge and confidence in dealing with the symptoms [129], and positively influence each other's hopes about the future, despite the limitations of the disease. Indeed, the support coming from sharing experiences with others has been shown to be constructive also for patient's family members [130-132]. However, finding peer support could be complicated when experiencing a rare disease [130-132], but there still are chances to recover, also thanks to all the associations that operate to bring the patients closer and fill this gap. Furthermore, the development of new technologies may be of help to connect patients and peers. 
In Italy, narcoleptic patients are grouped in the Associazione Italiana Narcolettici ed Ipersonni (AIN onlus, http://www.narcolessia.org/). The association now gives support to many narcoleptic patients, representing not only the opportunity to be in contact with other people who share the same condition but also a place where sleep experts can cooperate and share information about different and specific case/symptoms, and thus improve their knowledge of the disease. This network was founded by the father of a young patient, after considerable efforts made to find a diagnosis and a cure. Today, the AIN is very active also at international level. Indeed, the AIN is working to spread the connections with other European narcoleptic patient associations, through eNAP, the new European Narcolepsy Alliance for Patient (https://narcolepsy.eu/). Furthermore, we report the website address of other important patient support associations:

- Austria: www.narkolepsie.at

- Belgium: www.narcolepsie-cataplexie.be

- Denmark: www.dansknarkolepsiforening.dk

- France: www.anc-narcolepsie.com

- Germany: http://www.dng-ev.de/

- Ireland: http://soundireland.ie/

- Netherlands: www.narcolepsie.nl

- Norway: http://www.sovnforeningen.no/

- Poland: http://www.narkolepsja.pl/

- Spain: http://www.narcolepsia.org/

- Sweden: http://www.narkolepsiforeningen.se/

- Switzerland: https://www.snane.ch/

- UK: www.narcolepsy.org.uk

- USA: NORD (National Organization for Rare Disorders): https://rarediseases.org/rare-diseases/narcolepsy/

- USA: Wake up Narcolepsy: https://www.wakeupnarcolepsy. org/

- USA: Narcolepsy Network: www.narcolepsynetwork.org

- USA: Project Sleep: https://project-sleep.com/

In summary, the following intervention is proposed for patients with narcolepsy, to be adopted especially in a multidisciplinary sleep medicine center. The first choice is pharmacological treatment with the integration of behavioral strategies for EDS and night sleep management. For those patients with impaired quality of life, anxiety-depressive comorbidity, and serious consequences on emotional and working life, pharmacological treatment should be integrated with a CBT treatment, focused on the cognitive and psychopathological consequences of narcolepsy. In addition, a counseling service and focus group therapy centered on peer support should be offered to increase the awareness of the disease condition, the patient's personal esteem, and a proper management of drug therapy, in terms of safety and compliance to the medication therapy.

\section{Child and Relatives}

Narcolepsy has a major negative impact on the child's social realm. Parents and caregivers facing child problems could undergo truly overwhelming stress levels, for the problems expressed that they cannot fully understand or detect.

Moreover, professional figures do not always offer enough support to the child, probably due to the rarity of the disorder and the consequent focus that physicians have to invest in the diagnostic and medical challenges. Encouragements mainly come from close family members who may be unprepared to meet the child's worries.

Kippola-Pääkkönen and colleagues studied the expectations and perceive support of children with narcolepsy after the pandemic influenza in Finland [133]. In their research, they proposed educational, psychological, and social interventions: lectures, individual psychosocial counseling, group discussions, and skill training. Also, parents completed a baseline (58) and a final (40) questionnaire. Findings reported that parents' worries were focused on the impact of narcolepsy on coping skills and the limitation of their time as a couple. In addition, parents received most of the support from their partners (77\%), then from sleep physicians (27\%) or teachers and school educators $(23 \%)$. Then, researchers recommended offering psychological support to patients also during the hospitalizations in order to help families obtain informal and professional support.

The 20-40\% incidence of depressive symptoms in narcoleptic pediatric patients [134] should encourage the scientific community to build a task force of experts that tries to understand the most disabling aspects of childhood or adolescent narcolepsy, such as access to drugs, symptom management with peer and family, school management of scheduled naps or management of drug therapy during school trips, psychopathological symptoms and their support, and support for families with access to peer help groups.

\section{Conclusions}

NT1 is a rare chronic disorder characterized by EDS, cataplexy, hypnagogic hallucinations, sleep paralysis, and disrupted night-time sleep [1]. For its diagnosis, multiple sleep latency test (MSLT) and polysomnography (PSG) are used $[1,36,134]$. The occurrence of hallucinations and sleep paralysis shifts in terms of frequency and impact in narcoleptic patients. In some cases, sodium oxybate turned out to be effective in reducing the number of hallucinations during the day [135], but other therapies, such as venlafaxine, also have a good therapeutic effect [28].

A recent review of the literature on disrupted nighttime sleep in patients with narcolepsy has shown that nocturnal sleep is characterized-both in PSG and subjective 
reports-by frequent brief awakenings, awakenings, and a high level of light sleep, which is also associated with poor quality of sleep at night [135]. Sodium oxybate seems to be a gold standard treatment in consolidating nocturnal sleep $[38,74,75]$.

Today, narcolepsy is still a complex disease, and despite new scientific discoveries about its pathophysiology, currently available treatments remain scarce and only symptomatic. Moreover, many drugs used in the clinical practice to cure children are still prescribed as "off-label" treatments.

Furthermore, new immune-modulating and hypocretin replacement treatments should be verified more systematically [89], especially in patients and children with recentonset narcolepsy in order to figure out their potential in treating the disease. Non-pharmacological interventions as well have been shown to contribute in helping patients and family members and to have a role in improving patients' quality of life, so for the future, it is advisable that outcome measures and multicompetent interventions should be guaranteed to patients and their families [17, 105].

Recently, research to find proper treatments for rare disorders has received a new attention from the European Union that has addressed programs and policies also to this area of health programs and policies, in order to balance attention between rare and common disorders (European Commission, 2014) [136].

Supplementary Information The online version contains supplementary material available at https://doi.org/10.1007/s13311-021-01051-4.

Required Author Forms Disclosure forms provided by the authors are available with the online version of this article.

\section{Declarations}

Conflict of Interest CF, FP, and FC declare that they have no conflict of interest. GP participated in advisory board for UCB Pharma, Jazz Pharmaceuticals, Bioprojet, and Takeda, outside the submitted work.

\section{References}

1. AASM: American Academy of Sleep Medicine. ICSD-3: international classification of sleep disorders, 3rd edn. Amer Acad Sleep Med, Daniel (IL) 2014.

2. Hagan JJ, Leslie RA, Patel S, et al. Orexin A activates locus coeruleus cell firing and increases arousal in the rat. Proc Natl Acad Sci U S A 1999;96:10911-10916.

3. Sutcliffe JG, de Lecea L. The hypocretins: excitatory neuromodulatory peptides for multiple homeostatic systems, including sleep and feeding. J Neurosci Res 2000;62:161-168.

4. Brown RE, Sergeeva O, Eriksson KS, Haas HL. Orexin A excites serotonergic neurons in the dorsal raphe nucleus of the rat. Neuropharmacology 2001;40:457-459.
5. Dye TJ, Gurbani N, Simakajornboon N. Epidemiology and Pathophysiology of Childhood Narcolepsy. Paediatr Respir Rev 2018;25:14-18.

6. Shibata M, Mondal MS, Date Y, Nakazato M, Suzuki H, Ueta Y. Distribution of orexins-containing fibers and contents of orexins in the rat olfactory bulb. Neurosci Res 2008;61:99-105.

7. Tashiro T, Kanbayashi T, Ijima S, Hishikawa Y. An epidemiological study of narcolepsy in Japanese. J Sleep Res 1992;1:228.

8. Mignot E. Genetic and familial aspects of narcolepsy. Neurology 1998;50:S16-S22.

9. Baumann CR, Mignot E, Lammers GJ, et al. Challenges in diagnosing narcolepsy without cataplexy: a consensus statement. Sleep 2014;37:1035-1042.

10. Miyagawa T, Tokunaga K. Genetics of narcolepsy. Hum Genome Var 2019;6:4.

11. Fronczek R, Arnulf I, Baumann CR, Maski K, Pizza F, Trotti LM. To split or to lump? Classifying the central disorders of hypersomnolence. Sleep 2020;43.

12. Dauvilliers Y, Jaussent I, Krams B, et al. Non-dipping blood pressure profile in narcolepsy with cataplexy. PLoS One 2012;7:e38977.

13. Rocca FL, Pizza F, Ricci E, Plazzi G. Narcolepsy during Childhood: An Update. Neuropediatrics 2015;46:181-198.

14. Ingravallo F, Gnucci V, Pizza F, et al. The burden of narcolepsy with cataplexy: how disease history and clinical features influence socio-economic outcomes. Sleep Med 2012;13:1293-1300.

15. Ton TGN, Watson NF, Koepsell TD, Longstreth WT. Narcolepsy and the Sickness Impact Profile: A general health status measure. Sleep Sci 2014;7:5-12.

16. Maski K, Steinhart E, Williams D, et al. Listening to the Patient Voice in Narcolepsy: Diagnostic Delay, Disease Burden, and Treatment Efficacy. J Clin Sleep Med 2017;13:419-425

17. Pascoe M, Bena J, Foldvary-Schaefer N. Effects of Pharmacotherapy Treatment on Patient-Reported Outcomes in a Narcolepsy and Idiopathic Hypersomnia Cohort. J Clin Sleep Med 2019;15:1799-806

18. Scammell TE, Estabrooke IV, McCarthy MT, et al. Hypothalamic arousal regions are activated during modafinil-induced wakefulness. J Neurosci 2000;20:8620-8628.

19. Wisor J. Modafinil as a catecholaminergic agent: empirical evidence and unanswered questions. Front Neurol 2013;4:139.

20. Billiard M, Bassetti C, Dauvilliers Y, et al. EFNS guidelines on management of narcolepsy. Eur J Neurol 2006;13:1035-1048.

21. Morgenthaler TI, Kapur VK, Brown T, et al. Practice parameters for the treatment of narcolepsy and other hypersomnias of central origin. Sleep 2007;30:1705-1711.

22. Schwartz JRL, Feldman NT, Bogan RK. Dose effects of modafinil in sustaining wakefulness in narcolepsy patients with residual evening sleepiness. J Neuropsychiatry Clin Neurosci 2005; 17:405-412.

23. Schwartz JRL, Feldman NT, Bogan RK, Nelson MT, Hughes RJ. Dosing regimen effects of modafinil for improving daytime wakefulness in patients with narcolepsy. Clin Neuropharmacol 2003;26:252-257.

24. Schwartz JRL, Nelson MT, Schwartz ER, Hughes RJ. Effects of modafinil on wakefulness and executive function in patients with narcolepsy experiencing late-day sleepiness. Clin Neuropharmacol 2004;27:74-79.

25. Billiard M, Besset A, Montplaisir J, et al. Modafinil: a doubleblind multicentric study. Sleep 1994;17:S107-S112.

26. Broughton RJ, Fleming JA, George CF, et al. Randomized, double-blind, placebo-controlled crossover trial of modafinil in the treatment of excessive daytime sleepiness in narcolepsy. Neurology 1997;49:444-451. 
27. Randomized trial of modafinil as a treatment for the excessive daytime somnolence of narcolepsy: US Modafinil in Narcolepsy Multicenter Study Group. Neurology 2000;54:1166-1175.

28. Beusterien KM, Rogers AE, Walsleben JA, et al. Health-related quality of life effects of modafinil for treatment of narcolepsy. Sleep 1999;22:757-765.

29. Thakrar C, Patel K, D'ancona G, et al. Effectiveness and sideeffect profile of stimulant therapy as monotherapy and in combination in the central hypersomnias in clinical practice. J Sleep Res 2018;27:e12627.

30. Palovaara S, Kivistö KT, Tapanainen P, Manninen P, Neuvonen PJ, Laine K. Effect of an oral contraceptive preparation containing ethinylestradiol and gestodene on CYP3A4 activity as measured by midazolam 1'-hydroxylation. Br J Clin Pharmacol 2000;50:333-337.

31. Harsh JR, Hayduk R, Rosenberg R, et al. The efficacy and safety of armodafinil as treatment for adults with excessive sleepiness associated with narcolepsy. Curr Med Res Opin 2006;22:761-774.

32. Dauvilliers Y, Bassetti C, Lammers GJ, et al. Pitolisant versus placebo or modafinil in patients with narcolepsy: a double-blind, randomised trial. Lancet Neurol 2013;12:1068-1075.

33. Szakacs Z, Dauvilliers Y, Mikhaylov V, et al. Safety and efficacy of pitolisant on cataplexy in patients with narcolepsy: a randomised, double-blind, placebo-controlled trial. Lancet Neurol 2017;16:200-207.

34. Lehert P, Szoeke C. Comparison of modafinil and pitolisant in narcolepsy: a non-inferiority meta-analytical approach. Drugs Context 2020;9.

35. Lin JS, Dauvilliers Y, Arnulf I, et al. An inverse agonist of the histamine $\mathrm{H}(3)$ receptor improves wakefulness in narcolepsy: studies in orexin-/- mice and patients. Neurobiol Dis 2008;30:74-83.

36. Syed YY. Pitolisant: First Global Approval. Drugs 2016;76:1313-1318.

37. Mamelak M, Escriu JM, Stokan O. The effects of gammahydroxybutyrate on sleep. Biol Psychiatry 1977;12:273-288.

38. Roth T, Dauvilliers Y, Guinta D, Alvarez-Horine S, Dynin E, Black J. Effect of sodium oxybate on disrupted nighttime sleep in patients with narcolepsy. J Sleep Res 2017;26:407-414.

39. Mansukhani MP, Kotagal S. Sodium oxybate in the treatment of childhood narcolepsy-cataplexy: a retrospective study. Sleep Med 2012;13:606-610.

40. US Xyrem Multicenter Study Group. A 12-month, open- label multicenter extension trial of orally administered sodium oxybate for the reatment of narcolepsy. Sleep 2003;26:31-35.

41. Xyrem International Study Group. Further evidence supporting the use of sodium oxybate for the treatment of cataplexy: a double-blind, placebo-controlled study in 228 patients. Sleep Med 2005;6:415-421.

42. U.S. Xyrem Multicenter Study Group. Sodium oxybate demonstrates long-term efficacy for the treatment of cataplexy in patients with narcolepsy. Sleep Med 2004;5:119-123

43. PDR.net. Available at: https://www.fda.gov/Drugs/DrugSafety/ ucm332029.htm 2016.

44. Plazzi G, Ruoff C, Lecendreux M, et al. Treatment of paediatric narcolepsy with sodium oxybate: a double-blind, placebo-controlled, randomised-withdrawal multicentre study and open-label investigation. Lancet Child Adolesc Health 2018;2:483-494.

45. Thorpy MJ, Shapiro C, Mayer G, et al. A randomized study of solriamfetol for excessive sleepiness in narcolepsy. Ann Neurol 2019;85:359-370.

46. Dauvilliers Y, Shapiro C, Mayer G, et al. Solriamfetol for the Treatment of Excessive Daytime Sleepiness in Participants with Narcolepsy with and without Cataplexy: Subgroup Analysis of Efficacy and Safety Data by Cataplexy Status in a Randomized Controlled Trial. CNS Drugs 2020;34:773-784.
47. Malhotra A, Shapiro C, Pepin JL, et al. Long-term study of the safety and maintenance of efficacy of solriamfetol (JZP-110) in the treatment of excessive sleepiness in participants with narcolepsy or obstructive sleep apnea. Sleep 2020;43.

48. Sleepfoundation.org. Sleep Apnea I National Sleep Foundation [online]. Available at: https://www.sleepfoundation.org/sleepdisorders-problems/sleep-apnea 2019.

49. Mitler MM, Shafor R, Hajdukovich R, Timms RM, Browman CP. Treatment of narcolepsy: objective studies on methylphenidate, pemoline, and protriptyline. Sleep 1986;9:260-264.

50. Leonard BE, McCartan D, White J, King DJ. Methylphenidate: a review of its neuropharmacological, neuropsychological and adverse clinical effects. Hum Psychopharmacol 2004;19:151-180.

51. Mayer G, Ewert Meier K, Hephata K. Selegeline hydrochloride treatment in narcolepsy. A double-blind, placebo-controlled study. Clin Neuropharmacol 1995;18:306-319.

52. Larrosa O, de la Llave Y, Bario S, Granizo JJ, Garcia-Borreguero D. Stimulant and anticataplectic effects of reboxetine in patients with narcolepsy: a pilot study. Sleep 2001;24:282-285,

53. Boscolo-Berto R, Viel G, Montagnese S, Raduazzo DI, Ferrara SD, Dauvilliers Y. Narcolepsy and effectiveness of gammahydroxybutyrate (GHB): a systematic review and meta-analysis of randomized controlled trials. Sleep Med Rev 2012;16:431-443.

54. Alshaikh MK, Tricco AC, Tashkandi M, Mamdani M, Straus SE, BaHammam AS. Sodium oxybate for narcolepsy with cataplexy: systematic review and meta-analysis. J Clin Sleep Med 2012:8:451-458.

55. US Xyrem Multicenter Study Group. A randomized, doubleblind, placebo-controlled multicenter trial comparing the effects of three doses of orally administered sodium oxybate with placebo for the treatment of narcolepsy. Sleep 2002;25:42-49.

56. Mayer G, Plazzi G, Iranzo Á, et al. Long-term compliance, safety, and tolerability of sodium oxybate treatment in patients with narcolepsy type 1: a postauthorization, noninterventional surveillance study. Sleep 2018;41.

57. Kollb-Sielecka M, Demolis P, Emmerich J, Markey G, Salmonson T, Haas M. The European Medicines Agency review of pitolisant for treatment of narcolepsy: summary of the scientific assessment by the Committee for Medicinal Products for Human Use. Sleep Med 2017;33:125-129.

58. Dauvilliers Y, Arnulf I, Szakacs Z, et al. Long-term use of pitolisant to treat patients with narcolepsy: Harmony III Study. Sleep 201921;42.

59. Langdon N, Shindler J, Parkes JD, Bandak S. Fluoxetine in the treatment of cataplexy. Sleep 1986;9:371-373.

60. Pillen S, Pizza F, Dhondt K, Scammell TE, Overeem S. Cataplexy and Its Mimics: Clinical Recognition and Management. Curr Treat Options Neurol 2017;19:23.

61. Wang J, Greenberg H. Status cataplecticus precipitated by abrupt withdrawal of venlafaxine. J Clin Sleep Med 2013;9:715-716.

62. Frey J, Darbonne C. Fluoxetine suppresses human cataplexy: a pilot study. Neurology 1994;44:707-709.

63. Thirumalai null, Shubin null. The use of citalopram in resistant cataplexy. Sleep Med 1 2000;1:313-316.

64. Poryazova R, Siccoli M, Werth E, Bassetti CL. Unusually prolonged rebound cataplexy after withdrawal of fluoxetine. Neurology 2005;65:967-968.

65. Schachter M, Parkes JD. Fluvoxamine and clomipramine in the treatment of cataplexy. J Neurol Neurosurg Psychiatry 1980;43:171-174.

66. Shapiro WR. Treatment of Cataplexy with Clomipramine. Arch Neurol 1975;32:653-656. 
67. Guilleminault C, Raynal D, Takahashi S, Carskadon M, Dement W. Evaluation of short-term and long-term treatment of the narcolepsy syndrome with clomipramine hydrochloride. Acta Neurol Scand 1976;54:71-87.

68. Lecendreux M, Bruni O, Franco P, et al. Clinical experience suggests that modafinil is an effective and safe treatment for paediatric narcolepsy. J Sleep Res 2012;21:481-483.

69. Aran A, Einen M, Lin L, Plazzi G, Nishino S, Mignot E. Clinical and therapeutic aspects of childhood narcolepsy-cataplexy: a retrospective study of 51 children. Sleep 2010;33:1457-1464.

70. Rugino T. A review of modafinil film-coated tablets for attention-deficit/hyperactivity disorder in children and adolescents. Neuropsychiatr Dis Treat 2007;3:293-301.

71. Ivanenko A, Tauman R, Gozal D. Modafinil in the treatment of excessive daytime sleepiness in children. Sleep Med 2003;4:579-582.

72. Inocente $\mathrm{C}$, Arnulf I, Bastuji $\mathrm{H}$, et al. Pitolisant, an inverse agonist of the histamine $\mathrm{H} 3$ receptor: an alternative stimulant for narcolepsy-cataplexy in teenagers with refractory sleepiness. Clin Neuropharmacol 2012;35:55-60.

73. Moresco M, Pizza F, Antelmi E, Plazzi G. Sodium Oxybate Treatment in Pediatric Type 1 Narcolepsy. Curr Drug Metab 2018;19(13):1073-1079.

74. Murali H, Kotagal S. Off-label treatment of severe childhood narcolepsy-cataplexy with sodium oxybate. Sleep 2006;29:1025-1029.

75. Antelmi E, Plazzi G, Pizza F, Vandi S, Aricò D, Ferri R. Impact of acute administration of sodium oxybate on heart rate variability in children with type 1 narcolepsy. Sleep Med 2018;47:1-6.

76. Filardi M, Pizza F, Antelmi E, Ferri R, Natale V, Plazzi G. In-field assessment of sodium oxybate effect in pediatric type 1 narcolepsy: an actigraphic study. Sleep 2018;41.

77. Dopheide JA, Pliszka SR. Attention-deficit-hyperactivity disorder: an update. Pharmacotherapy 2009;29:656-679.

78. Product information. Dextroamphetamine sulfate oral tablets, dextroamphetamine sulfate oral tablets. St. Louis, MO: Mallinckrodt 2007.

79. Product information. RITALIN: oral tablets, methylphenidate hydrochloride oral tablets. East Hanover, NJ: Novartis 2007.

80. Boaden K, Tomlinson A, Cortese S, Cipriani A. Antidepressants in Children and Adolescents: Meta-Review of Efficacy, Tolerability and Suicidality in Acute Treatment. Front Psychiatry 2020;11:717.

81. Ratkiewicz M, Splaingard M. Treatment of cataplexy in a threeyear-old using venlafaxine. J Clin Sleep Med 2013;9:1341-1342.

82. Møller LR, Østergaard JR. Treatment with venlafaxine in six cases of children with narcolepsy and with cataplexy and hypnagogic hallucinations. J Child Adolesc Psychopharmacol 2009;19:197-201.

83. Ristanovic RK, Liang H, Hornfeldt CS, Lai C. Exacerbation of cataplexy following gradual withdrawal of antidepressants: manifestation of probable protracted rebound cataplexy. Sleep Med 2009;10:416-421.

84. Dauvilliers Y, Carlander B, Rivier F, Touchon J, Tafti M. Successful management of cataplexy with intravenous immunoglobulins at narcolepsy onset. Ann Neurol 2004;56:905-908.

85. Plazzi G, Poli F, Franceschini C, et al. Intravenous high-dose immunoglobulin treatment in recent onset childhood narcolepsy with cataplexy. J Neurol 2008;255:1549-1554.

86. Knudsen S, Biering-Sørensen B, Kornum BR, et al. Early IVIg treatment has no effect on post-H1N1 narcolepsy phenotype or hypocretin deficiency. Neurology 2012;79:102-103.

87. Lecendreux M, Berthier J, Corny J, Bourdon O, Dossier C, Delclaux C. Intravenous Immunoglobulin Therapy in Pediatric Narcolepsy: A Nonrandomized, Open-Label,
Controlled, Longitudinal Observational Study. J Clin Sleep Med 2017;13:441-453.

88. Ruppert E, Zagala H, Chambe J, et al. Intravenous Immunoglobulin Therapy Administered Early after Narcolepsy Type 1 Onset in Three Patients Evaluated by Clinical and Polysomnographic Follow-Up. Behav Neurol 2018;2018:1671072.

89. Giannoccaro MP, Sallemi G, Liguori R, Plazzi G, Pizza F. Immunotherapy in Narcolepsy. Curr Treat Options Neurol. 2020 Jan 30;22(1):2.

90. Vignatelli L, Plazzi G, Peschechera F, Delaj L, D’Alessandro R. A 5-year prospective cohort study on health-related quality of life in patients with narcolepsy. Sleep Med 2011;12:19-23.

91. Ingravallo F, Plazzi G. Medico-legal aspects of disability in narcolepsy. In: Goswami M, Pandi- Perumal SR, Thorpy MJ, Narcolepsy: a clinical guide, New York, Springer Humana Press 2010;231-238.

92. Shneerson J. Narcolepsy and mental health. In: Goswami M, Pandi- Perumal SR, Thorpy MJ, Narcolepsy: a clinical guide. Springer Humana Press, New York 2010;239-250.

93. Lindsley G. Narcolepsy, intima1cy and sexuality. In: Goswami M, Pandi-Perumal SR, Thorpy MJ, Narcolepsy: a clinical guide, New York: Springer Humana Press 2010;205-216.

94. Donjacour C, Mets MAJ, Verster JC. Narcolepsy, driving and traffic safety. In: Goswami M, Pandi-Perumal SR, Thorpy MJ, Narcolepsy: a clinical guide, New York: Springer Humana Press 2010. p. 217-22.

95. Naumann A, Bellebaum C, Daum I. Cognitive deficits in narcolepsy. J Sleep Res 2006;15:329-338.

96. Bellebaum C, Daum I. Memory and cognition in narcolepsy. In: Goswami M, Pandi-Perumal SR, Thorpy MJ, Narcolepsy: a clinical guide. New York, Springer Humana Press 2010;223-230.

97. Dauvilliers Y, Paquereau J, Bastuji H, Drouot X, Weil JS, Viot-Blanc V. Psychological health in central hypersomnias: the French Harmony study. J Neurol Neurosurg Psychiatry 2009;80:636-641.

98. Ohayon MM. Narcolepsy is complicated by high medical and psychiatric comorbidities: a comparison with the general population. Sleep Med 2013;14:488-492.

99. Neikrug AB, Crawford MR, Ong JC. Behavioral Sleep Medicine Services for Hypersomnia Disorders: A Survey Study. Behav Sleep Med 2017;15:158-171

100. Alaia SL. Life Effects of Narcolepsy. null 1992;5:1-22.

101. Plazzi G, Fabbri C, Pizza F, Serretti A. Schizophrenia-like symptoms in narcolepsy type 1: shared and distinctive clinical characteristics. Neuropsychobiology 2015;71:218-224.

102. Bruck D, Broughton R. Achieving control over sleepiness in narcolepsy. Australian journal of primary health 2001;7:16-24.

103. Cohen FL, Nehring WM, Cloninger L. Symptom description and management in narcolepsy. Holist Nurs Pract 1996;10:44-53.

104. Daniels E, King MA, Smith IE, Shneerson JM. Health-related quality of life in narcolepsy. J Sleep Res 2001;10:75-81.

105. Postiglione E, Pizza F, Ingravallo F, et al. Impact of COVID-19 pandemic lockdown on narcolepsy type 1 management. Brain Behav 2021;11:e01955.

106. Britton T, Hansen A, Hicks J, Howard R, Meredith A. Guidelines on the diagnosis and management of narcolepsy in adults and children. Evidence-Based Guidelines for the UK with Graded Recommendations. Ashtead, UK: Taylor Patten Communications Ltd 2002.

107. Alóe F, Alves RC, Araújo JF, et al. [Brazilian guidelines for the treatment of narcolepsy]. Braz J Psychiatry 2010;32:305-314.

108. Rogers AE. Problems and coping strategies identified by narcoleptic patients. J Neurosurg Nurs 1984 Dec;16(6):326-34.

109. Kapella MC, Berger BE, Vern BA, Vispute S, Prasad B, Carley DW. Health-related stigma as a determinant of functioning in young adults with narcolepsy. PLoS One. 2015;10:e0122478. 
110. Marin-Agudelo H. Multicomponent Cognitive Behavioral treatment efficacy for narcolepsy (MCBT-N). Sleep Med 2011;12:S55.

111. Conroy DA, Novick DM, Swanson LM. Behavioral management of hypersomnia. Sleep Med Clin 2012;7:325-331.

112. Marı'n-Agudelo H, Jime'nez Correa U. Scheduled naps and systematic desensitization in the emotional processing in patients with narcolepsy: a comparative study of autonomic and cognitive evoked potentials. Sleep 2012;35: A275

113. Marín-Agudelo H, Jiménez Correa U. Beliefs and dysfunctional attitudes in patients with narcolepsy; double-blind study of treatment efficacy. Sleep 2013;36.

114. Ong JC, Dawson SC, Mundt JM, Moore C. Developing a cognitive behavioral therapy for hypersomnia using telehealth: a feasibility study. J Clin Sleep Med 2020;16:2047-2062.

115. Mullington J, Broughton R. Scheduled naps in the management of daytime sleepiness in narcolepsy-cataplexy. Sleep 1993 Aug;16(5):444-56.

116. Billiard M, Salva MQ, De Koninck J, Besset A, Touchon J, Cadilhac J. Daytime sleep characteristics and their relationships with night sleep in the narcoleptic patient. Sleep 1986;9(1 Pt 2):167-74.

117. Krahn LE, Hershner S, Loeding LD, et al. Quality measures for the care of patients with narcolepsy. J Clin Sleep Med 2015;11:335.

118. Helmus T, Rosenthal L, Bishop C, Roehrs T, Syron ML, Roth T. The alerting effects of short and long naps in narcoleptic, sleep deprived, and alert individuals. Sleep 1997;20:251-257.

119. Ebben MR. Nonpharmacologic Management of Excessive Daytime Sleepiness. Sleep Med Clin 2020;15:195-203.

120. Rogers AE, Aldrich MS, Lin X. A comparison of three different sleep schedules for reducing daytime sleepiness in narcolepsy. Sleep. 2001 Jun 15;24(4):385-91.

121. Chaiard J, Weaver TE. Update on Research and Practices in Major Sleep Disorders: Part II-Insomnia, Willis-Ekbom Disease (Restless Leg Syndrome), and Narcolepsy. J Nurs Scholarsh. 2019 Nov;51(6):624-33.

122. Uchiyama M, Mayer G, Meier-Ewert K. Differential effects of extended sleep in narcoleptic patients. Electroencephalogr Clin Neurophysiol 1994 Sep;91(3):212-218.

123. España RA, McCormack SL, Mochizuki T, Scammell TE. Running promotes wakefulness and increases cataplexy in orexin knockout mice. Sleep 2007 Nov;30(11):1417-25.

124. Filardi M, Pizza F, Antelmi E, Pillastrini P, Natale V, Plazzi G. Physical Activity and Sleep/Wake Behavior, Anthropometric, and Metabolic Profile in Pediatric Narcolepsy Type 1. Front Neurol 2018;9:707.

125. Broughton R J, Murray B J. The behavioral management of narcolepsy. In: Bassetti C L, Billard M, Mignot E, editors. Narcolepsy and hypersomnia. Informa Healthcare; 2007. pp. 497-512.
126. Marín Agudelo HA, Jiménez Correa U, Carlos Sierra J, PandiPerumal SR, Schenck CH. Cognitive behavioral treatment for narcolepsy: can it complement pharmacotherapy? Sleep Sci 2014 Mar;7(1):30-42.

127. Franceschini C, Fante C, Folli MC, Filosa M, Pizza F, Antelmi E, et al. Giving a voice to cataplectic experience: recollections from patients with narcolepsy type 1. J Clin Sleep Med. 2020 Apr 15;16(4):597-603.

128. Dennis CL. Peer support within a health care context: a concept analysis. Int J Nurs Stud 2003 Mar;40(3):321-32.

129. Franceschini C, Fante C, Filardi M, Folli MC, Brazzi F, Pizza F, et al. Can a Peer Support the Process of Self-Management in Narcolepsy? A Qualitative Narrative Analysis of a Narcoleptic Patient. Front Psychol. 2020;11:1353.

130. Embuldeniya G, Veinot P, Bell E, Bell M, Nyhof-Young J, Sale JEM, et al. The experience and impact of chronic disease peer support interventions: a qualitative synthesis. Patient Educ Couns 2013 Jul;92(1):3-12.

131. Shilling V, Morris C, Thompson-Coon J, Ukoumunne O, Rogers M, Logan S. Peer support for parents of children with chronic disabling conditions: a systematic review of quantitative and qualitative studies. Dev Med Child Neurol 2013 Jul;55(7):602-9.

132. Anderson M, Elliott EJ, Zurynski YA. Australian families living with rare disease: experiences of diagnosis, health services use and needs for psychosocial support. Orphanet J Rare Dis 2013 Feb $11 ; 8: 22$.

133. Kippola-Pääkkönen A, Härkäpää K, Valkonen J, Tuulio-Henriksson A, Autti-Rämö I. Psychosocial intervention for children with narcolepsy: Parents' expectations and perceived support. J Child Health Care 2016 Dec;20(4):521-9.

134. Szakács A, Hallböök T, Tideman P, Darin N, Wentz E. Psychiatric comorbidity and cognitive profile in children with narcolepsy with or without association to the H1N1 influenza vaccination. Sleep. 2015 Apr 1;38(4):615-21.

135. Roth T, Dauvilliers Y, Mignot E, Montplaisir J, Paul J, Swick T, et al. Disrupted nighttime sleep in narcolepsy. J Clin Sleep Med 2013 Sept 15;9(9):955-65.

136. European Commission. Implementation report on the Commission communication on rare diseases: Europe's challenges and Council Recommendation of 8 June 2009 on an action in the field of rare diseases. Available at: http://ec.europa.eu/health/ rare_diseases/docs/2014_rarediseases_implementationreport_ en.pd

Publisher's Note Springer Nature remains neutral with regard to jurisdictional claims in published maps and institutional affiliations. 